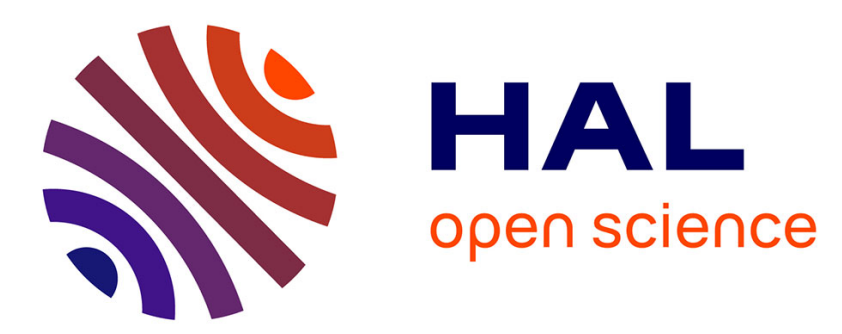

\title{
Patterned expression of Pannexin channels in the adult mouse cerebellar Purkinje cells
}

\author{
Visou Ady, David Dubayle, Pascale Le Blanc, Valery Shestopalov, Claude \\ Meunier, Carole Levenes
}

\section{- To cite this version:}

Visou Ady, David Dubayle, Pascale Le Blanc, Valery Shestopalov, Claude Meunier, et al.. Patterned expression of Pannexin channels in the adult mouse cerebellar Purkinje cells. 2019. hal-02415783

\section{HAL Id: hal-02415783 \\ https://hal.science/hal-02415783}

Preprint submitted on 17 Dec 2019

HAL is a multi-disciplinary open access archive for the deposit and dissemination of scientific research documents, whether they are published or not. The documents may come from teaching and research institutions in France or abroad, or from public or private research centers.
L'archive ouverte pluridisciplinaire HAL, est destinée au dépôt et à la diffusion de documents scientifiques de niveau recherche, publiés ou non, émanant des établissements d'enseignement et de recherche français ou étrangers, des laboratoires publics ou privés. 


\section{Patterned expression of Pannexin 1 channels in the}

\section{adult cerebellar Purkinje cells}

3

4

Visou Ady ${ }^{1,2}$, David Dubayle ${ }^{1,2}$, Pascale Le Blanc ${ }^{1,2}$, Valery Shestopalov ${ }^{3}$,

${ }^{1}$ Centre National de la Recherche Scientifique (CNRS), UMR 8119, Centre de Paris, France.

2 Université Paris Descartes, Faculté des Sciences Fondamentales et Biomédicales, 45 rue des Saints Pères, 75006 Paris, France. 


\section{Abstract}

Pannexin1 (PanX1) are recently discovered proteins that can form large pore

21 channels at the cell surface. They have been implicated in ATP-dependent cell-to-cell

22 communication and in several pathophysiological processes such as inflammation,

23 cell death and epilepsy. Using immunohistochemistry in the adult mouse, we

24 describe the presence of PanX1 in the deep cerebellar nuclei, in large cells of the

25 granular layer, presumably Golgi interneurones, in some Bergmann glia radial

26 processes as well as in the soma and dendrites of Purkinje cells. In the latter, PanX1,

27 like many other proteins, distribute heterogeneously. Only Zebrin II-positive Purkinje

28 cells express PanX1, in accordance with the so-called "zebra-striped" modular

29 architecture of the cerebellum. This distribution in zebra-stripes suggest that PanX1

30 may contribute to the control of ensemble activity within cerebellar microdomains or

31 to the response of Purkinje cell to excitotoxicity and cell-death messages. 


\section{Introduction}

Pannexins are membrane proteins ubiquitously present in vertebrate organisms. They were discovered in 2000 by sequence homology with the invertebrate innexins [1]. They show structural similarities with connexins [1] but do not seem to form gap-junctions in native cells ([2] and refs in [3]. Among the three types of pannexins described to date, pannexin 1 (PanX1) is by far the most studied. It is heavily expressed in the central nervous system, in both neurons and glial cells. Its mRNA has been detected in the retina, the cerebellum, the neocortex and

41 hippocampus, in the amygdala, substantia nigra and the olfactory bulb, [4-6, 7 , 8, 9, $10,11]$. PanX1 can be activated by cytoplasmic $\mathrm{Ca}^{2+}$, membrane depolarization, extracellular ATP and $\mathrm{K}^{+}$, by mechanical stretch and caspase cleavage $([12,13,14]$ and refs in [3]). They can form large conductance channels of up to $550 \mathrm{pS}$ [13] that carry non-selective ion fluxes and are permeable to molecules up to $1 \mathrm{kDa}$, including ATP itself $[14,15],[16]$. Once released, ATP can act on purinergic receptors or can be further degraded into adenosine by ectonucleotidases. Thus pannexins mediate auto- and paracrine communication, making them possible actors of retrograde neuronal communication and modulators of neuronal activity, for example through presynaptic adenosine receptors [17]. However, their exact physiological role remains unclear. Evidence shows that they can initiate $\mathrm{Ca}^{2+}$ waves, for instance after mechanical stretch [13], control the vascular tonus, regulate differentiation, cell death and immune function [3]. In pathological conditions, they may activate the 54 inflammasome ([12] reviewed in [18]), contribute to caspase-mediated apoptosis [19] and ischemic cell-death [20], and enhance epileptic seizures. They could also play a role as tumor suppressors (refs in [3]). 
In the cerebellum, PanX1 proteins are heavily expressed, particularly in

59 Purkinje cells [7, 10], but their contribution to cerebellar physiology or pathology

remains totally unknown. Despite its apparent homogeneous crystal-like organization,

61 the cerebellum is, in fact, highly compartmentalized. It displays genetically

62 determined and reproducible topographic domains: the transverse zones and

63 parasagittal stripes, including the cortical so-called zebra-stripes [21]. The latter can

64 be revealed by the patterned expression of numerous molecules, particularly in

Purkinje cells. Zebrin II, now known to be the respiratory enzyme Aldolase C, was the

first example of such a protein [22]. It is expressed in parasagittal bands of Purkinje

cells that extend throughout the cerebellar cortex, separated by bands of Zebrin II-

negative Purkinje cells. Many other proteins match Zebrin II Purkinje cells patterns.

69 For example, phospholipase C $\beta 4$ (PLC $\beta 4$; [23]), the metabotropic glutamate

receptor 1b (mGluR1b; [24]) and the early B-cell factor 2 (EbF2; [25]) are expressed

71 in Zebrin II-negative Purkinje cell stripes. On the other hand, PLC $\beta 3$ [26], the

72 excitatory amino-acid transporter 4 (EAAT4; [27]), and the GABA-B 1b receptor [28]

73 are expressed in Zebrin II-positive Purkinje cell. These striped distributions of

neurotransmitter receptors and their effectors indicate that Zebrin II-negative and -

positive Purkinje cells respond differentially to their inputs. For instance, the

glutamatergic climbing fibers that form synapses onto Zebrin II-positive Purkinje cells

77 release more glutamate per action potential than those terminating on Zebrin IInegative ones [29]. Zebrin II-positive Purkinje cells seem to be adapted to respond to increased glutamate inputs and to better resist death and neurodegeneration of various origins $[30,31,32,33]$. Sphingosine kinase, a lipid metabolism protein that

81 plays an important role in apoptosis, is also found selectively in Zebrin II-positive

82 Purkinje cells [30]. Overall, the proteins expressed in Zebrin II-positive Purkinje cells, 
83 including Zebrin II itself, seem to confer these cells capacities to respond to sustained

84 neuronal activity and to the associated increase in metabolic demand.

In the present study, we use a type of antibodies directed against the extreme cerebellum. These antibodies that had never been used in this structure reveal a zebra-striped pattern of PanX1 in Purkinje cells. This differential rostro-caudal expression,typical of the cerebellum, had never been described before for PanX1. It suggests that PanX1s contribute to the adaptation of Purkinje cells to the increased activity observed in the zebra stripes, and thus that pannexins may play important functions in the physiology and pathophysiology of the cerebellum.

93

\section{Materials and methods}

95

96

\section{Animals}

The animals used were all adult $(n=25)$ C57BL/6JRj males and females C57BL/6JRj mice (from 8 to 12 weeks of age), purchased at Janvier Laboratory (Le Genest-St-Isle, France). Mice were housed at the central animal facility of Les SaintsPères (Paris, France). Housing and all procedures were performed in accordance with the guidelines of the French Ministry of Agriculture and the European Community and have been approved by the ethical committee of Paris Descartes University (agreement: Paris Descartes \# 14-013). A minimal number of animals was used and they were handled with maximum care in order to minimize their suffering.

\section{Tissue preparation}

The animals were deeply anaesthetized with sodium pentobarbital $(175 \mathrm{mg} / \mathrm{Kg}$ 
107

108

109

\begin{tabular}{|c|c|c|c|}
\hline Antigen & Immunogen & $\begin{array}{c}\text { Source, host species, } \\
\text { RRID }\end{array}$ & Dilution \\
\hline Pannexin 1 & $\begin{array}{l}18 \mathrm{kDa} \text { C-terminal portion of } \\
\text { human Pannexin } 1 \text { protein }\end{array}$ & $\begin{array}{l}\text { Chemicon, Millipore, } \\
\text { USA ; rabbit polyclonal ; } \\
\text { affinity purified. } \\
\text { RRID : AB_2236635 }\end{array}$ & $1: 750$ \\
\hline Pannexin 1 & $\begin{array}{l}18 \text { kDa C-terminal portion of } \\
\text { human Pannexin } 1 \text { protein, } \\
\text { affigel-conjugated }\end{array}$ & $\begin{array}{l}\text { Dr. V. Schestopalov, } \\
\text { Miami, USA ; rabbit } \\
\text { polyclonal ; affinity } \\
\text { purified. } \\
\text { RRID : AB_2315054 }\end{array}$ & $1: 750$ \\
\hline Calbindin & Calbindin D-28k protein & $\begin{array}{l}\text { Swant, Switzerland; } \\
\text { mouse monoclonal. } \\
\text { RRID : AB_10000347 }\end{array}$ & $1: 7500$ \\
\hline $\begin{array}{c}\text { Zebrin II } \\
\text { (Aldolase C) }\end{array}$ & $\begin{array}{l}\text { Recognizes a single polypeptide } \\
\text { band of apparent molecular } \\
\text { weight } 36 \mathrm{kDa} \text { on cerebellum } \\
\text { homogenates from all vertebrate } \\
\text { classes studied with this } \mathrm{Ab} \text {. }\end{array}$ & $\begin{array}{l}\text { Dr. R. Hawkes, Calgary, } \\
\text { Canada ; mouse } \\
\text { monoclonal. } \\
\text { RRID : AB_2315622 }\end{array}$ & $1: 50$ \\
\hline
\end{tabular}

i.p.). The intracardiac perfusion consisted of $50 \mathrm{ml} 0.01 \mathrm{M}$ phosphate-buffered saline (PBS, pH: 7,4), followed by $50 \mathrm{ml}$ of $4 \%$ paraformaldehyde in $0.1 \mathrm{M}$ PBS. The cerebellum was removed, postfixed for 1 day in $4 \%$ paraformaldehyde solution and cryoprotected in a $30 \%$ sucrose phosphate-buffered solution at $4{ }^{\circ} \mathrm{C}$ for 2 days before cutting. The cerebellum was cut into longitudinal or sagittal $80 \mathrm{~mm}$-thick sections using a freezing sliding microtome (Frigomobil Reichert-Jung) and collected in plastic-wells containing PBS. Serial sections over the entire rostrocaudal length of the cerebellum were treated and analyzed.

\section{Antibody Characterization}

Table 1. Primary antibodies used in this study. 
antibody raised against the C-terminus of the human PanX1. The first one came from

121 Chemicon (USA). The second one was made by V. Schestopalov [11] as follows. A

122 rabbit polyclonal antibody against the carboxyl terminus of human PanX1 cDNA

123 encompassing the entire coding region was synthesized by PCR amplification of the

124 cDNA insert from clone IMAGE: 4390851 using two gene-specific primers (Px1F: 5'-

125 TCTGGATCCTACACGCTGTTTGTTCCA-3';

Px1R:

$5^{\prime}-$

126 TCTAAGCTTGCAAGAAGAATCCAGAAG-3'). It was then inserted into the BamHI and HindIII sites of pET-23a to yield the pETPx1 plasmid. The resultant $18 \mathrm{kDa}$ pETPx1 protein fused to the His-tagged C-terminus was purified from E. coli and used for immunization of the rabbit. The affinity purified rabbit serum containing specific anti-human PanX1 activity and lacking any significant non-specific activities was used for the immunohistochemistry. In the present study, we verified the specificity of the two PanX1 antibodies we used with their immunogenic peptide in western-blot and immunohistochemistry experiments (see results). The sequence of

134 the peptide corresponds to the 135 last amino-acids (C-ter) of the human PanX1 135 protein. Blasting this peptide sequence shows its high specificity for PanX1. The 136 specificity of PanX1 antibody was tested by peptide pre-adsorption: 1/2000 anti137 PanX1 was pre-incubated for $2 \mathrm{~h}$ at room temperature with $1 / 400$ of immunizing 138 peptide and then used for western-blot of $30 \mu \mathrm{g}$ of protein extract from adult mice cerebellum. The same peptide was used in immunohistochemistry with the same pre140 incubating procedure except that the PanX1 antibody was used at 1/750 and 141 blocking peptide dilutions were 1/750,1/150 and 1/75. Both anti-PanX1 antibodies 142 gave similar results. Therefore, data obtained with these to different antibodies were pooled. 


\section{Immunostaining for light microscopic analysis} expression analysis. Sections were first incubated in blocking buffer containing PBST-G (PBS 0.1\%, Triton X-100 0.25\%, Glycine $0.75 \%$ and gelatine from porcine skin $0.25 \%$, Sigma, UK) for 1 hour at room temperature. Following three washes in PBSG (PBS-T-G, without Triton), sections were incubated for 72 hours at room temperature in a mixture of the primary antibodies. Following three washes in PBS-G, the slices were incubated at room temperature for 2 hours with a mixture of secondary antibodies containing: anti-mouse Alexa fluor (AF) 546 (1:250) and antirabbit AF488 (1:250), both from Molecular Probes (USA). Following a final wash in PBS-G, the sections were air-dried and mounted in a homemade Mowiol-based processed with the ImageJ software (public domain: http://rsbweb.nih.gov/ij/). Final montages were made with Adobe Photoshop.

\section{Results}

\section{Distribution of PanX1 immunoreactivity: rostrocaudal}

\section{gradient and parasagittal stripes.} immunohistochemistry. In western blots of mouse cerebellar extracts, the PanX1 antibodies recognize a single $\sim 43 \mathrm{kDa}$ band as expected for PanX1 in brain extracts [11]. This band disappeared after incubating the antibodies with a saturating 
169

170

171

172

173

vanished with increasing concentrations of the blocking peptide in a dose-dependent manner (Fig 1B-E). We also verified that the blocking peptide did not interfere with the immunolabeling procedure by testing it with an antibody directed against parvalbulmin (Fig 1F). As expected, the peptide did not affect the parvalbumin labeling.

We next used the anti-PanX1 antibodies to assess the distribution of PanX1 in the cerebellum. As a marker of Purkinje cells, we used the calcium binding protein calbindin-D28k (CaBP). CaBP labeling also allowed us to verify the aspect of these cells and the quality of intracardial fixation. Confocal images of sagittal cerebellar slices made in the vermis revealed that PanX1 antibodies strongly label the soma and dendrites of Purkinje cells (Fig 2A), as previously observed [10, 34 ]. The labeling was spotty and more concentrated in proximal dendrites (Fig 2A,B). In distal branches, it was also detectable in the vicinity of spines at the level of the thin spiny branchlets (Fig 2B top insets). Remarkably, numerous PanX1 spots seemed to be located outside Purkinje cells themselves, in close apposition to their dendrites. This is suggestive of a possible PanX1-mediated communication between Purkinje cells spines and their afferences (Fig 2B top insets). Molecular layer interneurons were negative for PanX1 labeling (Fig 2B). The radial processes of some - but not all Bergman glial cells were immunoreactive for PanX1 (Fig 2B). Granule cells were devoid of labeling, but longitudinal sections revealed the presence of PanX1 in round cell bodies of the granular layer, presumably from Golgi cells (Fig 2C). In the deep cerebellar nuclei (DCN), Purkinje cell axons were strongly immunoreactive for PanX1, and some large cells immunopositive for CaBP were also reactive for PanX1 antibodies (Fig 2D). All these observations are in agreement with previous literature $[7,10,35,36]$ 
Intriguingly, and in contrast with previous data, PanX1 labeling of Purkinje cells was almost absent in the anterior cerebellar lobules, although well-shaped

Purkinje cells were present, as attested by CaBP labeling (Fig 3A). Mosaic

parasagittal images of entire cerebellar sections (Fig 3B) revealed a clear rostro-

caudal gradient of PanX1 labeling, in contrast to the homogeneous CaBP labeling.

This was particularly obvious in the vermis, when comparing the rostral lobule III (Fig

$3 \mathrm{~A}$ ) with the caudal lobule IX (Fig 3C). In the central and posterior lobules, PanX1

immunofluorescence was discontinuous, as PanX1-immunopositive zones were

lobule X was constant among slices and more pronounced than in the other lobules.

204

\section{Distribution of Pannexin1 labeling matches that of Zebrin II.}

The rostro-caudal heterogeneous expression pattern of PanX1 that we

observed in sagittal sections is reminiscent of that of the several tens of proteins

expressed in zebra stripes in the cerebellum (reviewed in [21]), the most studied being Zebrin II [22], identified as the Aldolase C enzyme [37]. The very name "Zebrin" comes from the zebra-like pattern that clearly appears in longitudinal sections., distribution, while that of CaBP appears homogeneous attesting the actual presence

213 of Purkinje cells in the overall slice (Fig 4). In those longitudinal sections, the floculi, 214 parafloculi and Crus II regions consistently appeared PanX1 positive (Fig 4A,D), 215 while lobules I to $\mathrm{V}$ displayed several little stripes of few immunopositive Purkinje 216 cells (Fig 4 B,C).

The profile of PanX1 distribution in rostral longitudinal section being typical of

218 that of Zebrin II, we made double labelings of these two proteins to compare their 
respective distributions using large scale mosaic imaging (Fig 5).

In parasagittal sections, the overall distribution of PanX1 matched that of

221 Zebrin II (Fig 5A). This was clear from lobule VIb to the posterior tip of lobule VII, and

222 in lobules VIII to X, where Purkinje cells where almost uniformly labeled. In other

223 lobules, there was sometimes a difference in the intensity of staining, which was

224 likely due to different subcellular distributions of Zebrin II and PanX1. However, 225 examination at higher magnification showed that the boundaries of strongly 226 immunoreactive bands and weakly immunoreactive (or unreactive) bands were very 227 similar for these two markers.

We made longitudinal sections in the rostral, medial and caudal parts of the cerebellum to verify if PanX1 and Zebrin II distributions matched over the whole 230 antero-posterior structure (Fig 5B-D). In rostral regions, most Purkinje cells were 231 Zebrin II-negative and PanX1-negative (Fig 5B). In the vermis, the midline and the 232 two lateral Zebrin II-positive bands on each side (presumably $\mathrm{P} 1+, \mathrm{P} 2+$ +, P3+ 233 according to [38]) were PanX1-positive and were separated by broad PanX1234 negative bands (lobule III or IV). In medial and caudal sections, staining in lobules 235 VIb, VII and X was uniform and dense across Purkinje cells (Fig 5C and D). In lobule 236 IX, the midline and the two lateral Zebrin II-positive bands were also PanX1-positive 237 (Fig 5D). Sections through the posterior and the nodular cerebellum showed perfect 238 match between PanX1- and Zebrin II-positive Purkinje cells (Fig 5D). In conclusion, the distribution of PanX1-positive Purkinje cells matches that of 240 Zebrin II-positive cells either in rostral, medial or caudal parts of the cerebellar cortex.

\section{Discussion}


244 glia processes and in scattered cells in the granular layer (likely Golgi interneurons)

$245[7,9,10,35,36]$. Our results are in agreement with previous literature for all cell

246 types expressing PanX1. However, we evidence for the first time a rostro-caudal

247 gradient in the distribution of PanX1 in cerebellar Purkinje cells. In our experiments,

248 PanX1 were almost undetectable in the anterior lobules but strongly labeled in the

249 caudal lobules, particularly in the posterior zone. This distribution matches that of the

250 standard in the subject, the Zebrin II protein, which is expressed according to a

251 striped pattern, highly reproducible and highly conserved across evolution [21]. To

our knowledge, the antibodies that we used here had only been tested before in the

retina [11], but never in the cerebellum. In our western-blots, made on adult

254 cerebellum protein extracts, the anti-PanX1 antibodies detect a $43 \mathrm{kDa}$ band as

255 expected for PanX1. In addition, we used the corresponding immunizing PanX1

256 peptide pre-adsorbed and incubated with the PanX1 antibody to verify specificity,

257 both in western-blot and in immunohistochemistry. In this latter set of experiments, 258 the dose-dependent blocking effect of the immunizing peptide further confirmed the 259 validity of our data.

Why the specific localization of PanX1 in Zebrin II-positive Purkinje cells has never been reported before is an intriguing question. It may be that our antibodies recognize a different subset of PanX1 isoform(s) compared to previous studies.

263 Several protein modifications explain the various banding patterns observed in 264 western-blots, such as pre- and post-translational modifications (glycosylation, S265 nitrosylation or caspase-mediated cleavage). PanX1 seems to be subjected to numerous splicing modifications. Besides the full-length variant named PanX1a (48 $267 \mathrm{kDa}$ ), alternative splicing of the human or rat PanX1 encoding genes generates at 268 least four variants (PanX1a-d), of predicted molecular weights of 48, 40, and $34 \mathrm{kDa}$ 
269 for PanX1a, 1c, and 1d respectively [39]. PanX1 can also be glycosylated and S-

270 nitrosylated, which modulates their surface expression and activity [34, 40]. This

271 could explain discrepancies between our study and the others published so far. Cone

272 et al. [34] made an elegant comparative analysis of labelings obtained with four

273 different antibodies in the adult mouse cerebellum, in which they show that different

274 polyclonal antibodies actually detect distinct species of PanX1. These antibodies

275 revealed various sub-cellular and cellular localization of PanX1, depending on the

276 epitope design. Our antibodies likely target a specific species that is restricted to

277 Zebrin II-positive Purkinje cells. PanX1 isoforms with molecular weight around 43

$278 \mathrm{kDa}$, like ours, likely corresponds to non - or weakly - glycosylated forms that tend to

279 be more confined to intracellular compartments [34] but can also reach the

280 membrane in some conditions [34, 41]. The species that we detect here seems to

281 reach the membrane because dendrites and spines were heavily stained in our

282 immunohistochemistry experiments.

The distribution of PanX1 proteins in zebra stripes is intriguing,. PanX1 have

284 been so far essentially implicated in pathologies. They have been shown to be

285 activated by pathological conditions such as epileptic seizures or infection [42, 43]. In

286 turn, once activated, they contribute to worsen these conditions. Their activation can

287 engage the inflammasome and trigger aptototic processes [44, 45] (see also [46]).

288 Zebrin II-positive Purkinje cells better resist to infectious and chemical injuries than

289 their Zebrin II-negative sisters and resist better to cell-death. Therefore, the

290 preferential localization of PanX1 in Zebrin II bands seems rather paradoxical, unless

291 the specific species of PanX1 we have evidenced there display a higher threshold for

292 activation. In this case, they would be less activated in pathological condition than

293 their Zebrin-II negative counterparts, thus rendering the Zebrin-II positive cells more 
resistant to insults. However, this remains an unsubstantiated hypothesis.

Another picture emerges if we consider instead the role of pannexins in normal conditions [3], rather than focus on their deleterious effects. PanX1 exert some of

297 their paracrine functions as ATP channels. ATP, which in turn activates PanX1, can

298 be hydrolyzed into ADP, AMP, and eventually in adenosine by ectonucleotidases.

299 These molecules are agonists of purinergic and adenosine receptors, known to modulate neuronal activity in the cerebellar cortex $[47,48]$. For example, adenosine receptors A1R, expressed at both pre- and post-synaptic sides glutamatergic afferences on Purkinje cells, decrease glutamate release [49] and inhibit long-term depression [50]. Thus pannexins could trigger the activation of presynaptic A1R by

304 releasing ATP - further converted into adenosine - and reduce glutamate release. In

305 this scheme, PanX1 would participate to a negative feedback control of synaptic transmission. Such a mechanism would provide a homeostatic regulation of neuronal 307 transmission in the cerebellum, as has recently been suggested elsewhere [51]. The presence of PanX1 in Zebrin II-positive regions could thus help neurons adapt to the increased activity observed in these microzones. It is striking that the majority of the

310 molecules present in parasagittal bands are directly involved in synaptic 311 transmission, control of neuronal activity, or cell responses to the associated 312 metabolic demand. The specific species of PanX1 present in zebrin II-bands may 313 well contribute to this adaptation.

314 In conclusion, we can hypothesize that the PanX1 species we have evidence 315 here provide Zebrin II-positive Purkinje cells with additional tools to adapt to the 316 specific physiology of this zone characterized by increased glutamate release, 317 enhanced metabolic demand and better resistance to cell-death. All these 318 possibilities remain hypotheses for the moment, but our data open new perspectives 
bioRxiv preprint first posted online Oct. 25, 2018; doi: http://dx.doi.org/10.1101/453738. The copyright holder for this preprint (which was not peer-reviewed) is the author/funder, who has granted bioRxiv a license to display the preprint in perpetuity.

All rights reserved. No reuse allowed without permission.

319 that call for further investigation.

320 
321 Figure Legends

Fig 1. Specificity of the anti-PanX1 antibody.

Western blot of mouse cerebellum extracts labeled with the PanX1-antibody.

A: The two left lanes correspond to PanX1 antibody alone (- BP); the two right lanes correspond to PanX1 antibody + blocking peptide (+ BP).

B: Confocal images of immunohistochemical labelings of PanX1 without blocking peptide. C-E: Confocal images with the same antibody incubated in the presence of increasing concentrations of the blocking peptide (dilutions as indicated). Images $B$ to $E$ were taken from Lobule X. F: Immunolabeling of parvalbumin (PV) protein made in the presence of the PanX1-blocking peptide (1/150). This control indicates that the blocking peptide does not inhibit any immunohistochemistry reaction but that directed against PanX1. Scale bar: $50 \mu \mathrm{m}$.

Fig 2. Cellular distribution of PanX1 in the cerebellar cortex.

A: Confocal images acquired in a PanX1 positive zone, PanX1 in green (top), dense punctiform PanX1 staining, notably in the spiny branchlets (top inserts). Notice the numerous PanX1 positive radial processes that are likely Bergman glial processes (white arrows in merged image, top center and bottom). C: Labeling in

341 longitudinal cerebellar sections confirms Purkinje cell staining and reveals round 342 middle size cells immunopositive for PanX1 (white arrows heads), presumably Golgi 343 cells. D: Fastigial deep cerebellar nucleus. Some large cells are immunopositive for 344 PanX1 (in green) and for CaBP in magenta (center). Smaller cells are also positive 345 for PanX1 but negative for CaBP (merged image, right). Notice the intense labeling of 
346 Purkinje cells axons. Scale bars in A : $50 \mu \mathrm{m}$; in B : $20 \mu \mathrm{m}$ and $10 \mu \mathrm{m}$ (inserts); C 347 and : $50 \mu \mathrm{m}$.

Fig 3. Localization of PanX1 in the cerebellum: dense labeling in Purkinje cells of the posterior lobules.

A: In lobule III, molecular layer displays very low PanX1 staining (green), although Purkinje cells are well present (CaBP, in magenta, was used as a Purkinje cell marker). B: Automated mosaic confocal images of sagittal slices from the cerebellar vermis region. White squares indicate the location of the high magnification confocal images shown in A (lobule III) and C (lobule IX).

C: Purkinje cells soma and dendrites in lobule IX display very strong PanX1 labeling. Scale bars

357 in A and B: $20 \mu \mathrm{m} \mathrm{B}$; in C: $500 \mu \mathrm{m}$.

Fig 4. Longitudinal cerebellar sections reveal striped PanX1 labeling.

A: Mosaic reconstructions of $\mathrm{CaBP}$ (magenta) and PanX1 (green) labeling show that PanX1 are distributed in subsets of several tens of Purkinje cells drawing stripes in lobules I-V. B, C and D are confocal images made in the regions indicated by white squares in $A$. Note the intense PanX1 labeling in Crus $I / I I$ and in the paraflocculi (PFI). DCN, deep cerebellar nucleus, Roman numbers indicate to corresponding lobules. Scale bars in A: $500 \mu \mathrm{m}, \mathrm{B}: 100 \mu \mathrm{m}, \mathrm{C}$ and D: $50 \mu \mathrm{m}$

Fig 5. PanX1 and Zebrin II distribution in Purkinje cells match throughout the cerebellum. Images are mosaic reconstruction made from confocal images. A: Zebrin II and PanX1 immunolabeling colocalize in Purkinje cells in a sagittal cerebellar slice 
taken in the vermis. B: Same colocalization observed in a longitudinal slice made in

372 the rostral part of the cerebellum. C, D: Same as in B but in the medial and caudal parts of the cerebellum respectively. Lobules are indicated as Roman numbers; PFI, paraflocculus; Sim, lobulus simplex; Cop, copula pyramidis; PM, lobulus paramedianum; FN, fastigial nucleus. Scale bars in B to F: $500 \mu \mathrm{m}$.

\section{Acknowledgements}

We thank Richard Hawkes for the kind gift of the anti-Zebrin II antibody as well as precious recommendations. We also thank David Hansel for critical reading and comments on the manuscript. We sincerely acknowledge the imaging facility SCM

(Service Commun de Microscopie - Faculté des Sciences Fondamentales et Biomédicales - Paris) and specially Jean-Maurice Petit.

\section{References}

1. Panchin Y, Kelmanson I, Matz M, Lukyanov K, Usman N, Lukyanov S. A ubiquitous family of putative gap junction molecules. Current Biology. 2000;10(13):R473-4. PubMed PMID: 10898987.

388 2. Sosinsky GE, Boassa D, Dermietzel R, Duffy HS, Laird DW, MacVicar B, et al. Pannexin channels are not gap junction hemichannels. Channels. 2011;5(3):193-7. PubMed PMID: 21532340; PubMed Central PMCID: PMC3704572. 3. Penuela S, Gehi R, Laird DW. The biochemistry and function of pannexin channels. Biochim Biophys Acta. 2013;1828(1):15-22. doi: 10.1016/j.bbamem.2012.01.017. PubMed PMID: 22305965. mammalian pannexin family is homologous to the invertebrate innexin gap junction proteins. Genomics. 2004;83 (4):706-16. doi: 10.1016/j.ygeno.2003.09.025. PubMed PMID: 15028292. 5. Bruzzone R, Hormuzdi SG, Barbe MT, Herb A, Monyer H. Pannexins, a family of gap junction proteins expressed in brain. Proc Natl Acad Sci U S A. 2003;100(23):13644-9. doi: 10.1073/pnas.2233464100. PubMed PMID: 14597722; PubMed Central PMCID: PMC263867. 6. Zoidl G, Petrasch-Parwez E, Ray A, Meier C, Bunse S, Habbes HW, et al. Localization of the pannexin1 protein at postsynaptic sites in the cerebral cortex and hippocampus. Neuroscience. 2007;146(1):9-16. doi: 10.1016/j.neuroscience.2007.01.061. PubMed PMID: 17379420.

404 7. Vogt A, Hormuzdi SG, Monyer H. Pannexin1 and Pannexin2 expression in the developing 
and mature rat brain. Brain Res Mol Brain Res. 2005;141(1):113-20. doi: 10.1016/j.molbrainres.2005.08.002. PubMed PMID: 16143426.

8. Shestopalov VI, Panchin Y. Pannexins and gap junction protein diversity. Cellular and molecular life sciences : CMLS. 2008;65(3):376-94. doi: 10.1007/s00018-007-7200-1. PubMed PMID: 17982731.

410 9. Ray A, Zoidl G, Wahle P, Dermietzel R. Pannexin expression in the cerebellum. Cerebellum. 2006;5(3):189-92. doi: 10.1080/14734220500530082. PubMed PMID: 16997749. 10. Ray A, Zoidl G, Weickert S, Wahle P, Dermietzel R. Site-specific and developmental expression of pannexin 1 in the mouse nervous system. Eur J Neurosci. 2005;21 (12):3277-90. doi: 10.1111/j.1460-9568.2005.04139.x. PubMed PMID: 16026466.

11. Dvoriantchikova G, Ivanov D, Panchin Y, Shestopalov VI. Expression of pannexin family of proteins in the retina. FEBS Lett. 2006;580(9):2178-82. doi: 10.1016/j.febslet.2006.03.026. PubMed PMID: 16616526.

12. Silverman WR, de Rivero Vaccari JP, Locovei S, Qiu F, Carlsson SK, Scemes E, et al. The pannexin 1 channel activates the inflammasome in neurons and astrocytes. J Biol Chem. 2009;284(27):18143-51. doi: 10.1074/jbc.M109.004804. PubMed PMID: 19416975; PubMed Central PMCID: PMC2709345.

13. Bao L, Locovei S, Dahl G. Pannexin membrane channels are mechanosensitive conduits for ATP. FEBS Lett. 2004;572(1-3):65-8. doi: 10.1016/j.febslet.2004.07.009. PubMed PMID: 15304325.

14. Locovei S, Bao L, Dahl G. Pannexin 1 in erythrocytes: function without a gap. Proc Natl Acad Sci U S A. 2006;103(20):7655-9. doi: 10.1073/pnas.0601037103. PubMed PMID: 16682648; PubMed Central PMCID: PMC1472500. 15. MacVicar BA, Thompson RJ. Non-junction functions of pannexin-1 channels. Trends Neurosci. 2010;33(2):93-102. doi: 10.1016/j.tins.2009.11.007. PubMed PMID: 20022389. 16. Chiu YH, Ravichandran KS, Bayliss DA. Intrinsic properties and regulation of Pannexin 1 channel. Channels. 2014;8(2):103-9. doi: 10.4161/chan.27545. PubMed PMID: 24419036; PubMed Central PMCID: PMC4048298.

17. Kawamura M, Jr., Ruskin DN, Masino SA. Metabolic autocrine regulation of neurons involves cooperation among pannexin hemichannels, adenosine receptors, and KATP channels. J Neurosci. 2010;30(11):3886-95. doi: 10.1523/JNEUROSCI.0055-10.2010. PubMed PMID: 20237259; PubMed Central PMCID: PMC2872120.

18. Adamson SE, Leitinger $N$. The role of pannexin 1 in the induction and resolution of inflammation. FEBS Lett. 2014;588(8):1416-22. doi: 10.1016/j.febslet.2014.03.009. PubMed PMID: 24642372; PubMed Central PMCID: PMC4060616.

440 19. Chekeni FB, Elliott MR, Sandilos JK, Walk SF, Kinchen JM, Lazarowski ER, et al. Pannexin 4411 channels mediate 'find-me' signal release and membrane permeability during apoptosis. Nature. 2010;467 (7317):863-7. doi: 10.1038/nature09413. PubMed PMID: 20944749; PubMed Central PMCID: PMC3006164.

20. Bargiotas P, Krenz A, Monyer H, Schwaninger M. Functional outcome of pannexindeficient mice after cerebral ischemia. Channels. 2012;6(6):453-6. doi: 10.4161/chan.22315. PubMed PMID: 23111424; PubMed Central PMCID: PMC3536730.

21. Apps R, Hawkes R. Cerebellar cortical organization: a one-map hypothesis. Nature reviews Neuroscience. 2009;10(9):670-81. doi: 10.1038/nrn2698. PubMed PMID: 19693030.

22. Brochu G, Maler L, Hawkes R. Zebrin II: a polypeptide antigen expressed selectively by Purkinje cells reveals compartments in rat and fish cerebellum. J Comp Neurol. 1990;291 (4):538-52. doi: 10.1002/cne.902910405. PubMed PMID: 2329190.

23. Marzban H, Chung S, Watanabe M, Hawkes R. Phospholipase Cbeta4 expression reveals the continuity of cerebellar topography through development. J Comp Neurol. 2007;502 (5):857-71. doi: 10.1002/cne.21352. PubMed PMID: 17436294. 
24. Mateos JM, Osorio A, Azkue JJ, Benítez R, Elezgarai I, Bilbao A, et al. Parasagittal compartmentalization of the metabotropic glutamate receptor mGluR1b in the cerebellar cortex. European Journal of Anatomy. 2001;5(1):7. 25. Croci L, Chung SH, Masserdotti G, Gianola S, Bizzoca A, Gennarini G, et al. A key role for the HLH transcription factor EBF2COE2,0/E-3 in Purkinje neuron migration and cerebellar cortical topography. Development. 2006;133(14):2719-29. doi: 10.1242/dev.02437. PubMed PMID: 16774995.

26. Sarna JR, Marzban H, Watanabe M, Hawkes R. Complementary stripes of phospholipase Cbeta3 and Cbeta4 expression by Purkinje cell subsets in the mouse cerebellum. J Comp Neurol. 2006;496(3):303-13. doi: 10.1002/cne.20912. PubMed PMID: 16566000.

27. Nagao S, Kwak S, Kanazawa I. EAAT4, a glutamate transporter with properties of a chloride channel, is predominantly localized in Purkinje cell dendrites, and forms parasagittal compartments in rat cerebellum. Neuroscience. 1997;78 (4):929-33. PubMed PMID: 9174061.

28. Fritschy JM, Meskenaite V, Weinmann O, Honer M, Benke D, Mohler H. GABAB-receptor splice variants GB1a and GB1b in rat brain: developmental regulation, cellular distribution and extrasynaptic localization. Eur J Neurosci. 1999;11 (3):761-8. PubMed PMID: 10103070.

29. Paukert M, Huang YH, Tanaka K, Rothstein JD, Bergles DE. Zones of enhanced glutamate release from climbing fibers in the mammalian cerebellum. J Neurosci. 2010;30(21):7290-9. doi: 10.1523/JNEUROSCI.5118-09.2010. PubMed PMID: 20505095; PubMed Central PMCID: PMC2894469.

30. Terada N, Banno Y, Ohno N, Fujii Y, Murate T, Sarna JR, et al. Compartmentation of the mouse cerebellar cortex by sphingosine kinase. J Comp Neurol. 2004;469(1):119-27. doi: 10.1002/cne.11002. PubMed PMID: 14689477.

31. Chung SH, Calafiore M, Plane JM, Pleasure DE, Deng W. Apoptosis inducing factor deficiency causes reduced mitofusion 1 expression and patterned Purkinje cell degeneration. Neurobiol Dis. 2011;41(2):445-57. doi: 10.1016/j.nbd.2010.10.016. PubMed PMID: 20974255; PubMed Central PMCID: PMC3014456.

32. Sarna J, Miranda SR, Schuchman EH, Hawkes R. Patterned cerebellar Purkinje cell death in a transgenic mouse model of Niemann Pick type A/B disease. Eur J Neurosci. 2001;13(10):1873-80. PubMed PMID: 11403680.

33. Tolbert DL, Ewald M, Gutting J, La Regina MC. Spatial and temporal pattern of Purkinje cell degeneration in shaker mutant rats with hereditary cerebellar ataxia. J Comp Neurol. 1995;355 (4):490-507. doi: 10.1002/cne.903550403. PubMed PMID: 7636028.

34. Cone AC, Ambrosi C, Scemes E, Martone ME, Sosinsky GE. A comparative antibody analysis of pannexin1 expression in four rat brain regions reveals varying subcellular localizations. Frontiers in pharmacology. 2013;4:6. doi: 10.3389/fphar.2013.00006. PubMed PMID: 23390418; PubMed Central PMCID: PMC3565217.

35. Bunse S, Locovei S, Schmidt M, Qiu F, Zoidl G, Dahl G, et al. The potassium channel subunit Kvbeta3 interacts with pannexin 1 and attenuates its sensitivity to changes in redox potentials. The FEBS journal. 2009;276(21):6258-70. doi: 10.1111/j.17424658.2009.07334.x. PubMed PMID: 19780818.

36. Zappala A, Cicero D, Serapide MF, Paz C, Catania MV, Falchi M, et al. Expression of pannexin 1 in the CNS of adult mouse: cellular localization and effect of 4-aminopyridineinduced seizures. Neuroscience. 2006;141(1):167-78. doi: 10.1016/j.neuroscience.2006.03.053. PubMed PMID: 16690210.

37. Ahn AH, Dziennis $S$, Hawkes $R$, Herrup $K$. The cloning of zebrin II reveals its identity with aldolase C. Development. 1994;120(8):2081-90. PubMed PMID: 7925012.

38. Leclerc N, Dore L, Parent A, Hawkes R. The compartmentalization of the monkey and rat cerebellar cortex: zebrin I and cytochrome oxidase. Brain Res. 1990;506(1):70-8. PubMed PMID: 2154279. 
39. Li S, Tomic M, Stojilkovic SS. Characterization of novel Pannexin 1 isoforms from rat pituitary cells and their association with ATP-gated P2X channels. General and comparative endocrinology. 2011;174(2):202-10. doi: 10.1016/j.ygcen.2011.08.019. PubMed PMID: 21907716; PubMed Central PMCID: PMC3195874.

509 40. Lohman AW, Weaver JL, Billaud M, Sandilos JK, Griffiths R, Straub AC, et al. Snitrosylation inhibits pannexin 1 channel function. J Biol Chem. 2012;287 (47):39602-12. doi: 10.1074/jbc.M112.397976. PubMed PMID: 23033481; PubMed Central PMCID: PMC3501028. 41. Penuela S, Bhalla R, Gong XQ, Cowan KN, Celetti SJ, Cowan BJ, et al. Pannexin 1 and pannexin 3 are glycoproteins that exhibit many distinct characteristics from the connexin family of gap junction proteins. J Cell Sci. 2007;120(Pt 21):3772-83. doi: 10.1242/jcs.009514. PubMed PMID: 17925379.

42. Thompson RJ, Jackson MF, Olah ME, Rungta RL, Hines DJ, Beazely MA, et al. Activation of pannexin-1 hemichannels augments aberrant bursting in the hippocampus. Science. 2008;322 (5907):1555-9. doi: 10.1126/science.1165209. PubMed PMID: 19056988. 43. Aquilino MS, Whyte-Fagundes P, Zoidl G, Carlen PL. Pannexin-1 channels in epilepsy. Neurosci Lett. 2017. doi: 10.1016/j.neulet.2017.09.004. PubMed PMID: 28886985.

44. Dahl G, Keane RW. Pannexin: from discovery to bedside in 11+/-4 years? Brain Res. 2012;1487:150-9. doi: 10.1016/j.brainres.2012.04.058. PubMed PMID: 22771709; PubMed Central PMCID: PMC3590907. Pannexin1 as mediator of inflammation and cell death. Biochim Biophys Acta. 2017;1864(1):51-61. doi: 10.1016/j.bbamcr.2016.10.006. PubMed PMID: 27741412.

46. Shestopalov VI, Slepak VZ. Molecular pathways of pannexin1-mediated neurotoxicity. Frontiers in physiology. 2014;5:23. doi: 10.3389/fphys.2014.00023. PubMed PMID: 24575045; PubMed Central PMCID: PMC3920106.

47. Deitmer JW, Brockhaus J, Casel D. Modulation of synaptic activity in Purkinje neurons by ATP. Cerebellum. 2006;5(1):49-54. doi: 10.1080/14734220500497456. PubMed PMID: 16527764.

48. Donato R, Rodrigues RJ, Takahashi M, Tsai MC, Soto D, Miyagi K, et al. GABA release by basket cells onto Purkinje cells, in rat cerebellar slices, is directly controlled by presynaptic purinergic receptors, modulating Ca2+ influx. Cell Calcium. 2008;44(6):521-32. doi: 10.1016/j.ceca.2008.03.006. PubMed PMID: 18468677.

49. Kocsis JD, Eng DL, Bhisitkul RB. Adenosine selectively blocks parallel-fiber-mediated synaptic potentials in rat cerebellar cortex. Proc Natl Acad Sci U S A. 1984;81(20):6531-4. PubMed PMID: 6093104; PubMed Central PMCID: PMC391958. 50. Kamikubo Y, Shimomura T, Fujita Y, Tabata T, Kashiyama T, Sakurai T, et al. Functional cooperation of metabotropic adenosine and glutamate receptors regulates postsynaptic plasticity in the cerebellum. J Neurosci. 2013;33(47):18661-71. doi: 10.1523/JNEUROSCI.5567-12.2013. PubMed PMID: 24259587.

51. Shestopalov VI, Panchin Y, Tarasova OS, Gaynullina D, Kovalzon VM. Pannexins Are Potential New Players in the Regulation of Cerebral Homeostasis during Sleep-Wake Cycle. Frontiers in cellular neuroscience. 2017;11:210. doi: 10.3389/fncel.2017.00210. PubMed PMID: 28769767; PubMed Central PMCID: PMC5511838. 
A
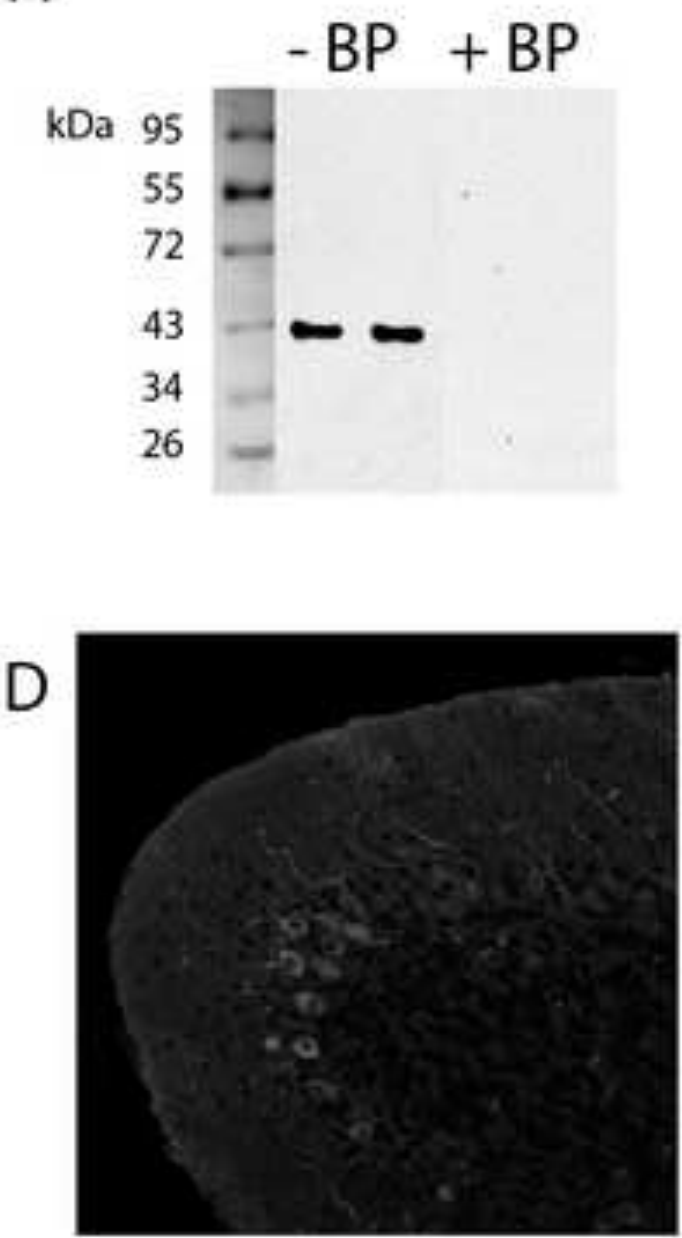

1/150 BP
B

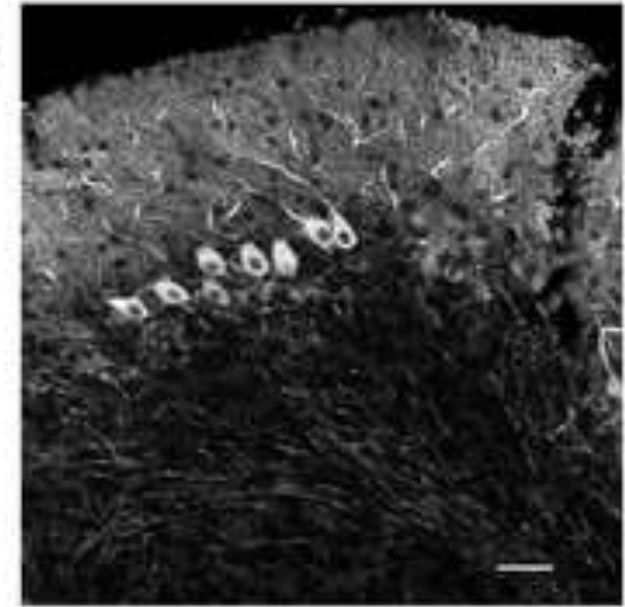

No BP

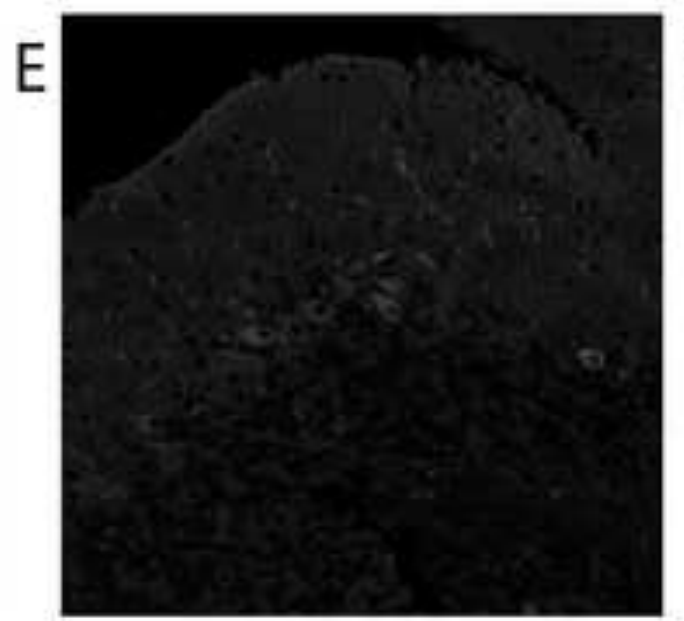

1/75 BP

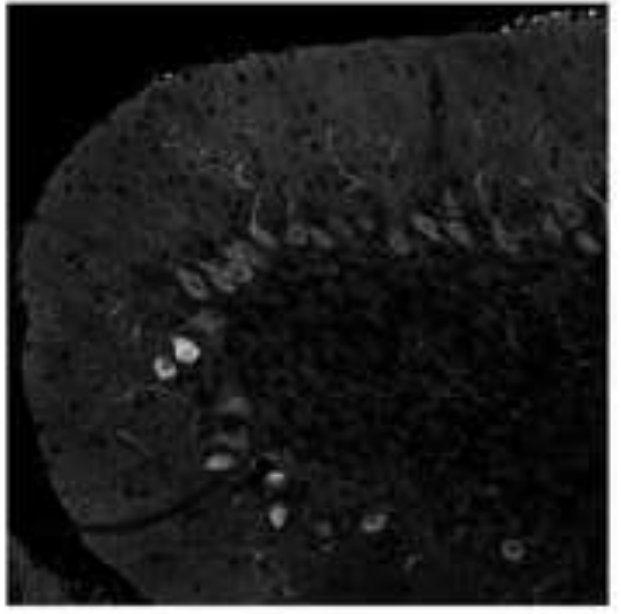

1/750 BP

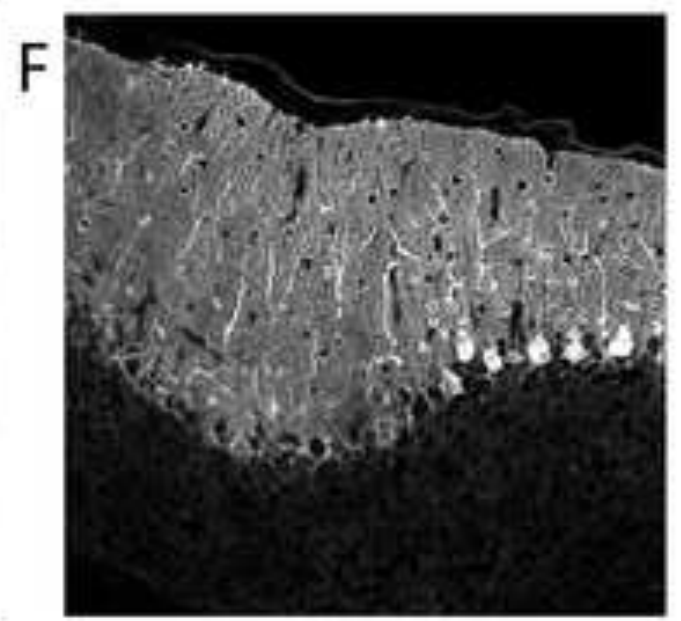

1/150 BP + anti-PV 


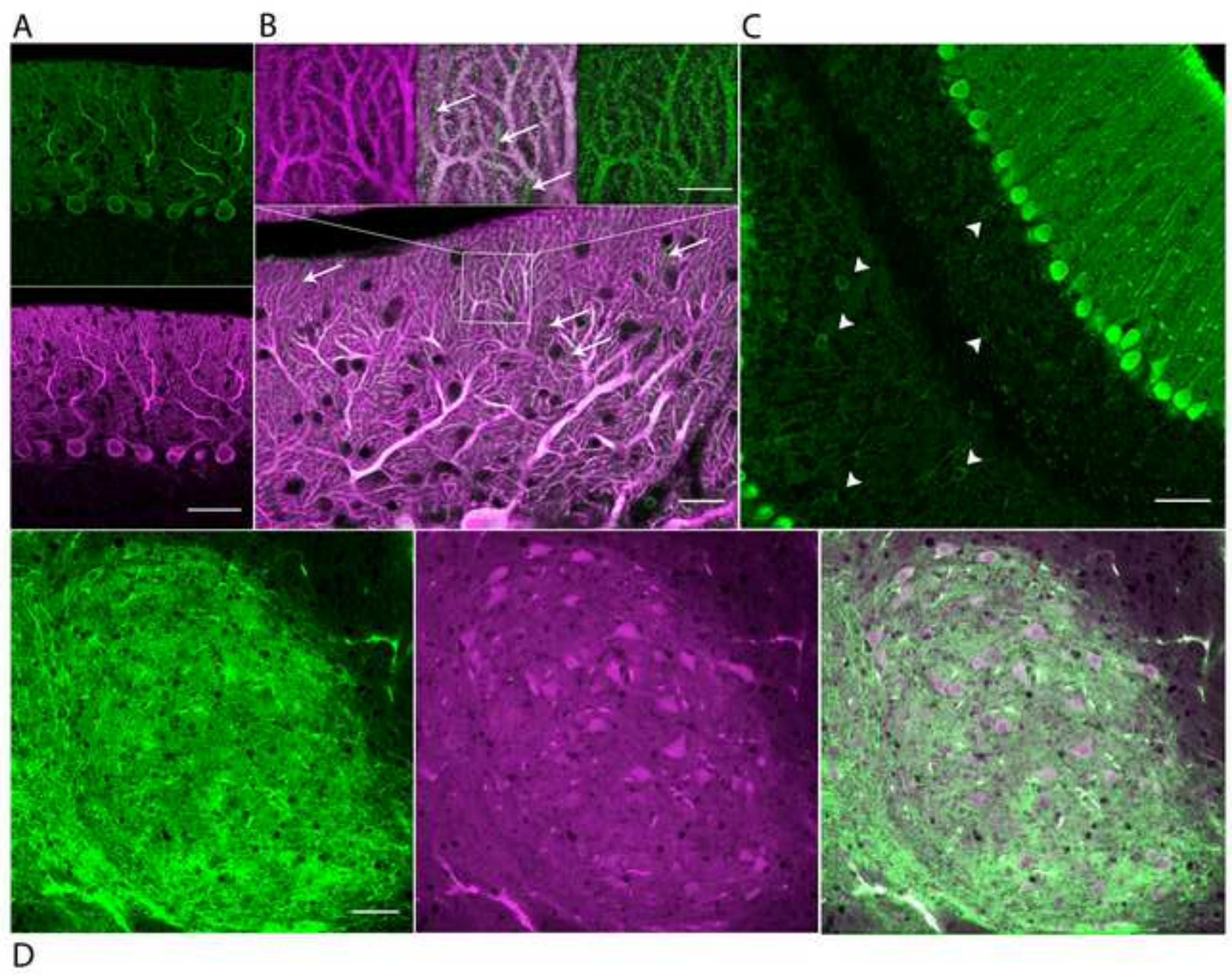




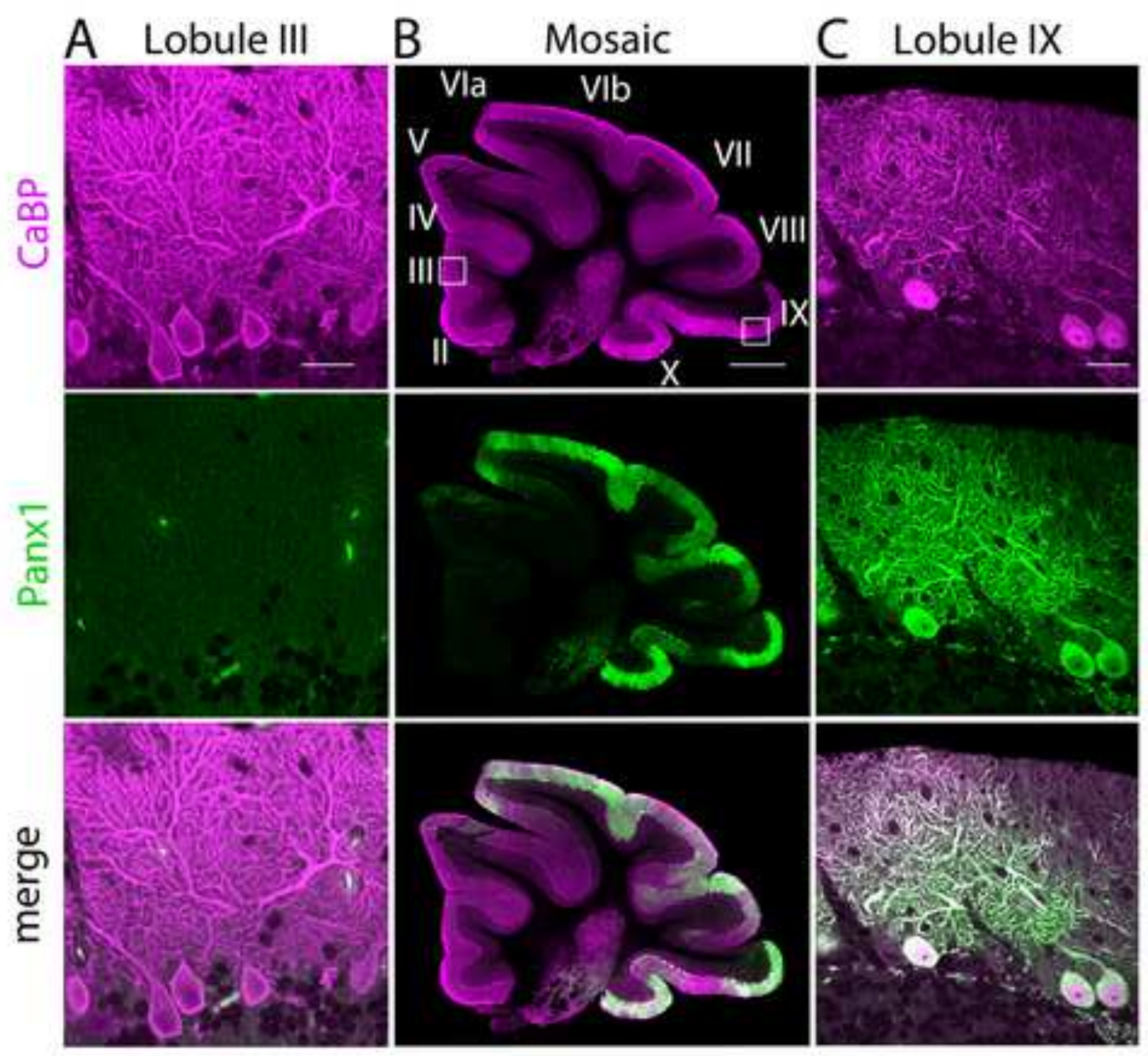



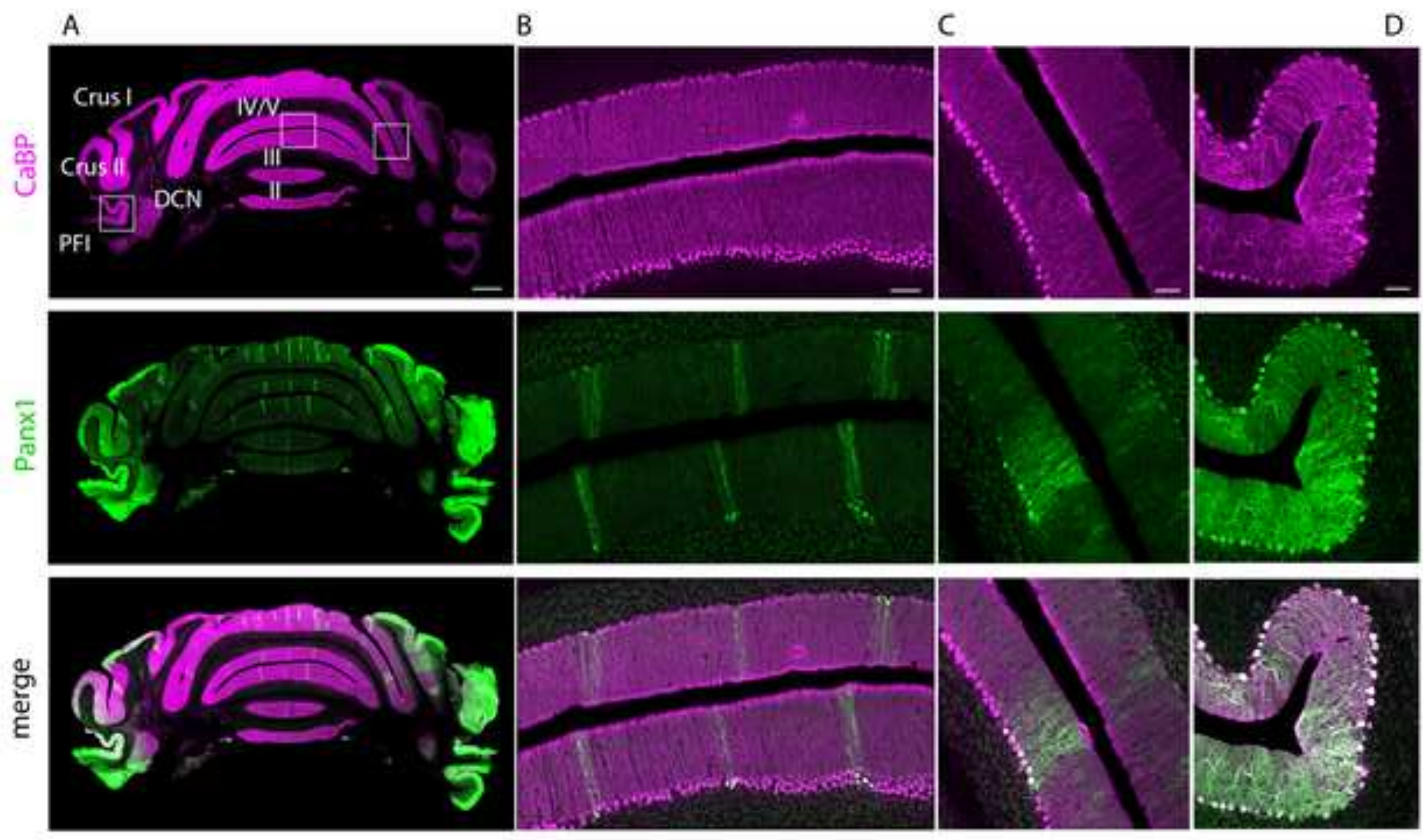


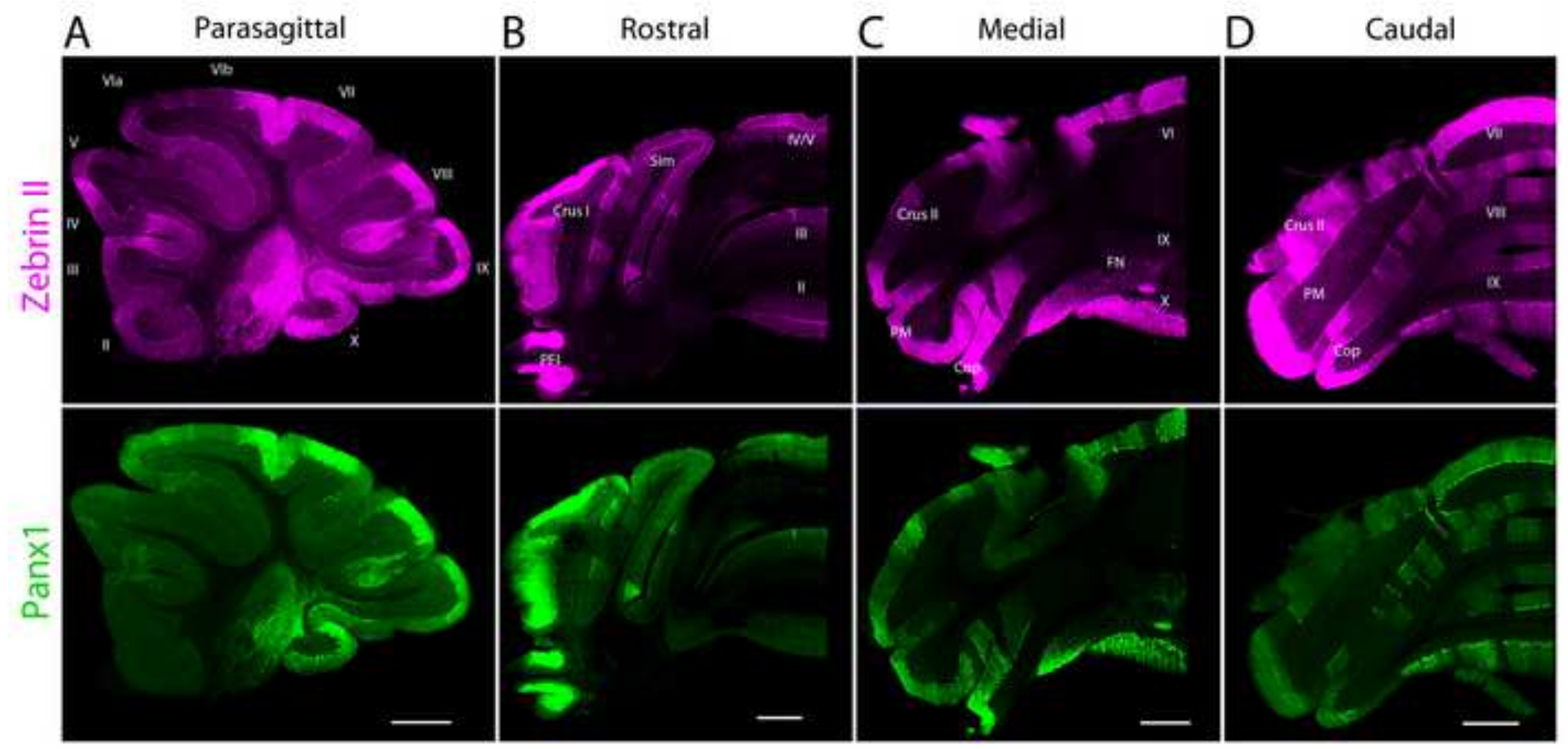

